\section{ICA12(SOX13) autoantibodies are unlikely to be a useful marker for pre-clinical Type I diabetes}

Dear Sir,

SOX13 (ICA12) belongs to the family of SRY-related HMG box protein transcription factors and has been reported as an autoantigen in a minority of patients with Type I (insulin-dependent) diabetes mellitus $[1,2]$. Recently, a study was made of antibodies to SOX13 in patients with Type I diabetes and control disease groups. The study reported that antibody reactivity could be found in a minority of patients but such antibodies were not specific for Type I diabetes and questioned the relevance of SOX13 antibodies as markers of Type I diabetes [3]. We also cloned the full-length human SOX13 cDNA and measured antibody binding to ${ }^{35} \mathrm{~S}$ methionine-labelled in vitro transcribed and translated protein by immunoprecipitation. We found antibody binding that reached very high levels (> 100 units; $>2000 \mathrm{cpm}$ vs $100 \mathrm{cpm}$ in negative sera) in a minority of 156 patients with new onset Type I diabetes confirming both reports (Fig. 1). We also found sera from control subjects and patients with Type II (non-insulin-dependent) diabetes mellitus exhibiting high antibody binding and a relatively broad range of binding was seen for all groups tested. Nevertheless, using the $99^{\text {th }}$ centile of binding from 176 control children as a threshold for positivity, we found that SOX13 antibodies increased in $12(7.6 \%)$ of 156 patients with new onset Type I diabetes $(p<0.005$ vs control children, Fisher's exact test), in none of 98 patients with Type I diabetes and in none of 100 adult control subjects (provided by M.P. Garancini) [4], suggesting that antibody reactivity could increase in autoimmune diabetes. The 12 patients with higher ICA12 antibody levels were significantly older than ICA12 negative patients (mean age 16 yrs vs 11 yrs, $p=0.04$ ), and predominantly female $(n=9)$ giving an overall prevalence in female patients aged 10 years or more of $24 \%$. This increased prevalence in adolescent female patients would be consistent with findings of antibodies in rheumatic diseases which are prevalent in adolescent females. Other investigators suggested that SOX13 antibodies potentially identified patients without antibodies to the major Type I diabetes-associated autoantigens insulin, GAD and IA-2 [2]. Only 2 of the 12 patients with a higher level of SOX13 antibodies from our cohort did not have autoantibodies to at least one of these autoantigens. We conclude, therefore, that whereas we can identify a subgroup of patients with Type I diabetes in whom SOX13 antibodies are not uncommon, these antibodies are likely to be one of a number of

Corresponding author: V. Lampasona, MD, Laboratorio di Genetica Molecolare 2, Laboratorio Centrale, Ospedale San Raffaele, via Olgettina 60, 20132 Milano, Italy

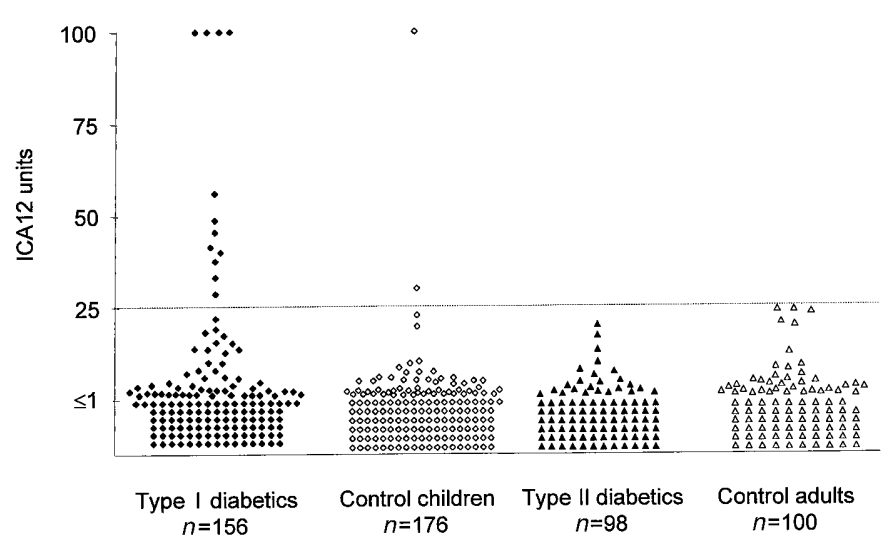

Fig. 1. SOX13 antibody binding levels in 156 patients with new onset Type I diabetes (median age 10; range 0.8-55), 176 control children (median age 4.5; range 0.1-11.2), 98 Type II diabetes patients (median age 64; range 40-87), and 100 adult control subjects (median age 58; range 40-80). Antibodies were detected by immunoprecipitation using in vitro transcribed and translated antigen. Results are expressed as arbitrary units derived from a standard curve with a positive Serum. The broken line indicates the 99th centile of control children

minor responses to non-islet specific autoantigens seen in Type I diabetes and are not likely to be a useful marker for preclinical Type I diabetes.

Yours faithfully,

V. Lampasona, M. Scirpoli, E. Bosi, E. Bonifacio

\section{References}

1. Rabin DU, Pleasic SM, Palmer-Crocker R, Shapiro JA (1992) Cloning and expression of IDDM-specific human autoantigens. Diabetes 41 (2): 183-186

2. Kasimiotis H, Myers MA, Argentaro A, Mertin S, Fida S, Ferraro T, Olsson J, Rowley MJ, Harley VR (2000) Sex-determining region Y-related protein SOX13 is a diabetes autoantigen expressed in pancreatic islets. Diabetes 49 (4): $555-561$

3. Steinbrenner H, Lohmann T, Ostendorf B, Scherbaum WA, Seissler J (2000) Autoantibodies to ICA12 (SOX13) are not specific for type 1 diabetes. Diabetologia in press

4. Garancini MP, Calori G, Ruotolo G, Manara E, Izzo A, Ebbli E, Bozzetti AM, Boari L, Lazzari P, Gallus G (1995) Prevalence of NIDDM and impaired glucose tolerance in Italy: an OGTT-based population study. Diabetologia 38: 306-313 